\title{
Application of a New Functionalized MWCNTs for the Construction of Surfactant Potentiometric Sensors
}

\author{
Sanja Petrušić,* Mirela Samardžić, Aleksandar Széchenyi, Milan Sak-Bosnar
}

\author{
Department of Chemistry, Josip Juraj Strossmayer University of Osijek, Cara Hadrijana 8A, HR-31000 Osijek, Croatia \\ * Corresponding author's e-mail address: spetrus@kemija.unios.hr
}

RECEIVED: May 15, 2017 * REVISED: June 30, 2017 * ACCEPTED: July 4, 2017

THIS PAPER IS DEDICATED TO PROF. MIRJANA METIKOŠ-HUKOVIĆ ON THE OCCASION OF HER BIRTHDAY

\begin{abstract}
The multi-walled carbon nanotubes (MWCNTs) were noncovalently functionalized with tetraoctadecylammonium tetraphenylborate (TODA-TPB) used as a sensing element and incorporated into a liquid PVC membrane of the new fast, low drift and sensitive potentiometric sensor (FCNSS) for anionic surfactants (ASs). The sensor exhibits a sub-Nernstian response for both dodecyl sulfate (DS) and dodecylbenzenesulfonate in $\mathrm{H}_{2} \mathrm{O}$ and in $10 \mathrm{mM} \mathrm{Na}_{2} \mathrm{SO}_{4}$.

The lower limits of detection for DS and DBS in $\mathrm{H}_{2} \mathrm{O}$ were $1.5 \cdot 10^{-7}$ and $2.0 \cdot 10^{-7} \mathrm{M}$ and in $10 \mathrm{mM} \mathrm{Na}_{2} \mathrm{SO}_{4}$, they were $2.0 \cdot 10^{-7} \mathrm{M}$ for both surfactants. The response time of the sensor varied between 8 and $12 \mathrm{~s}$, depending on AS concentration and its signal drift was 2.1 $\mathrm{mV} /$ hour. The FCNSS exhibited excellent selectivity for DS against nearly all anions usually found in commercial products. It was successfully employed for end-point detection at potentiometric titrations of ASs in detergent products and effluents.
\end{abstract}

Keywords: tetraoctadecylammonium tetraphenylborate, MWCNT, anionic surfactant sensor, potentiometric titration, industrial products, effluents.

\section{INTRODUCTION}

$\mathrm{N}$ recent years, the global surfactants market experienced steady growth. In 2015 it was valued at approximately USD 30.65 billion.[1] Among all types of surfactants, anionic surfactants (ASs) are the most commonly used ones. Their properties make them essential in a large variety of applications, especially in detergent industry. Analysis of ASs is, therefore, of great importance for industry and environmental protection. The standard methods for their determination are the methylene blue active substances method (MBAS) and the two-phase titration. ${ }^{[2,3]}$ Due to many disadvantages of the standard methods, ASs are usually determined using other analytical approaches (potentiometric titration, ${ }^{44,5]}$ chromatography, ${ }^{[6,7]}$ flow-injection analysis, ${ }^{[8,9]}$ spectrophotometry, ${ }^{[10,11]}$ biosensors, ${ }^{[12,13]}$ etc.). Ion-selective electrodes (ISEs) as sensors in potentiometric titrations represent simple, cheap and rapid alternative to the standard methods. The membrane is the most important part of the electrode, and usually consists of an ionophore as a sensing component, polyvinyl chloride (PVC) and a plasticizer.[14,15] The proportions of these parts can be varied, or some extra additives can be included in the membrane composition with the aim of developing the electrode with better properties (selectivity, limit of detection, response time, accuracy, lifetime, working range, etc.). Lately, the nanomaterials are widely used in various applications, due to their specific properties. ${ }^{[16,17]}$ They are also suitable for modifying the membranes of the ISEs because of their ability to reduce the signal drift, noise and electrical resistance, improve dynamic response and other response characteristics of the electrode and to prevent leaching of the sensing material from the membrane which leads to prolonged lifetime of the electrode. ${ }^{[18,19]}$

In this paper, multi-walled carbon nanotubes (MWCNTs) were noncovalently functionalized with tetraoctadecylammonium tetraphenylborate (TODA-TPB)

(c) Br $\mathbf{B Y}$ This work is licensed under a Creative Commons Attribution 4.0 International License. 
and used as sensing material in the liquid membrane electrode. The new electrode based on MWCNTs was potentiometrically characterized and it's applicability as a sensor for anionic surfactant determination was tested by potentiometric titrations of pure systems, commercial products and effluents.

\section{MATERIALS AND METHODS}

\section{Materials}

Poly vinyl chloride (PVC), o-nitrophenyloctylether (oNPOE), tetrahydrofurane (THF), tetraoctadecylammonium bromide (TODAB), sodium tetraphenylborate (NaTPB), sodium dodecyl sulfate ( $\mathrm{NaDS}$ ) and dodecylbenzenesulfonate (NaDBS), 1,3-didecyl-2-methylimidazolium chloride (DMIC), hexadecyltrimethylammonium bromide (CTAB) and benzethonium chloride (Hyamine 1622) were purchased from Fluka, Switzerland. Cetylpyridinium chloride (CPC) was obtained from Merck, Germany. Hexane and sodium decanesulfonate, dodecanesulfonate and tetradecanesulfonate were products of Sigma-Aldrich, USA. Genapols (T 080, T 110 and T 150) were purchased from Clariant, Switzerland. All the reagents used were of analytical grade except for NaDBS and Genapols which were of technical grade.

Real samples were liquid soap, liquid handdishwashing agent, gel detergent and three samples of household effluents.

MWCNTs (OD = 10-20 nm, L = 1-2 $\mu \mathrm{m}, 95+\%)$ were obtained from lo-li-tec, Germany.

Deionized water was used for the preparation of all solutions.

Philips electrode body IS-561 was obtained from Glasblaeserei Moeller, Zurich, Switzerland.

\section{Electrode Preparation}

MWCNTs were cleaned with $n$-hexane and dried at $60^{\circ} \mathrm{C}$. In the saturated solution of TODAB, the cleaned MWCNTs were added and stirred on magnetic stirrer until the mixture was homogenous. The mixture was then centrifuged.

The separated MWCNT-TODAB mixture was diluted with distilled water, stirred and $\operatorname{NaTPB}\left(c=1 \cdot 10^{-3} \mathrm{M}\right)$ was added till mixture MWCNT-TODA-TPB was separated. The separated mixture was dried for 24 hours at $60^{\circ} \mathrm{C}$.

The liquid membrane that consisted of $0.0584 \mathrm{~g}$ of PVC, $0.1170 \mathrm{~g}$ of $o-N P O E, 2 \mathrm{~mL}$ of THF and $0.0054 \mathrm{~g}$ of MWCNT-TODA-TPB mixture was mounted on the electrode body. Sodium chloride $(c=3 \mathrm{M})$ was used as the internal filling solution of the electrode.

The electrode prepared in such a way had a six months lifetime. Between the measurements, the electrode was kept in deionized water.

\section{Apparatus}

Centrifuge Centric 200R (Tehtnica, Slovenia) and magnetic stirrer RCT basic (IKA Labortechnik, Germany) were used for sensor material preparation. All potentiometric measurements were performed using the 794 Basic Titrino combined with Metrohm 806 Exchange unit, 801 stirrer with stand and 826 mobile pH meter (all from Metrohm, Switzerland). Tiamo (Metrohm, Switzerland) and in-house software were controlling the 794 Basic Titrino.

\section{Potentiometric Measurements}

All measurements were performed at room temperature with the new electrode used as the working electrode and a silver/silver chloride electrode used as the reference. All solutions were magnetically stirred during the measurements. There was no ionic strength or $\mathrm{pH}$ adjustments, except in titrations of real samples where $\mathrm{pH}$ was adjusted to 3 .

The new electrode response characteristics toward $\mathrm{NaDS}$ and $\mathrm{NaDBS}$ were examined in water and $\mathrm{Na}_{2} \mathrm{SO}_{4}(c=$ $0.01 \mathrm{M})$. Measuring of the signal drift was carried out in $\operatorname{NaDS}(c=1 \mathrm{mM})$. The total volume of the analyzed solution was always $20 \mathrm{~mL}$ during the response measurements.

The potentiometric selectivity coefficients for possible interfering anions $(c=0.01 \mathrm{M})$ were determined using the fixed interference method proposed by the IUPAC. [20]

$\mathrm{NaDS}$, three commercial products and three household effluent samples were used as analytes and four cationic surfactants (CPC, DMIC, CTAB and Hyamine) were used as titrants in the potentiometric titrations. The titrant concentrations used were $4 \cdot 10^{-3} \mathrm{M}, 4 \cdot 10^{-4} \mathrm{M}$ and $1 \cdot 10^{-4}$ M. During all titrations, the total solution volume was 25 $\mathrm{mL}$. Dynamic (DET) and monotonic equivalence point titration mode (MET) were used for potentiometric titration measurements. DET mode was accompanied with a signal drift of $5 \mathrm{mV} / \mathrm{min}$ and was used for determination of high concentrations of ASs. The increments of the titrant in MET mode were $0.1 \mathrm{~mL}$. MET mode was used for determination of low concentrations of ASs.

\section{RESULTS AND DISCUSSION}

\section{Response characteristics}

The analysis of ionic surfactants is most frequently based on the so called antagonist reaction:

$\mathrm{CAT}^{+}+\mathrm{AN}^{-} \rightleftarrows \mathrm{CATAN}$

where $\mathrm{CAT}^{+}$and $\mathrm{AN}^{-}$are large organic, mostly surfactant cations and anions, respectively.

The formed CATAN product is an ion-pair, slightly dissociated and almost insoluble in water but easily soluble in many organic solvents. In titrimetric methods, ASs are 
usually determined using standard solutions of cationic surfactants, as titrants.

The response of the ion-pair based ionic surfactant potentiometric sensors to cationic and anionic surfactants can be defined by the Nernst equation:

$E=E^{\circ}+S \cdot \log a\left(\mathrm{CAT}^{+}\right)$, for cationic surfactants

and

$E=E^{\circ}-S \cdot \log a\left(\mathrm{AN}^{-}\right)$, for anionic surfactants

where $a\left(\mathrm{CAT}^{+}\right)$and $a\left(\mathrm{AN}^{-}\right)$are activities of the cationic and anionic surfactant ions.

The solubility product of a $C A T^{+} A N^{-}$ion pair, used as the sensing element of a sensor membrane is

$K_{\mathrm{sp}}=a\left(\mathrm{CAT}^{+}\right) \cdot a\left(\mathrm{AN}^{-}\right)$

From Eq. (4), $a\left(\mathrm{CAT}^{+}\right)=K_{\mathrm{sp}} / a\left(\mathrm{AN}^{-}\right)$, and after its insertion into Eq. (2), the following sensor response is obtained:

$E=E^{\circ}+S \cdot \log K_{\mathrm{sp}} / a\left(\mathrm{AN}^{-}\right)$, which after rearrangement gives:

$E=$ const $-S \cdot \log a\left(\mathrm{AN}^{-}\right)$

where const $=E^{\circ}+S \cdot \log K_{\mathrm{sp}}$

where $E^{\circ}=$ constant potential term, $S=$ sensor slope, which for surfactant anion amounts $59.2 \mathrm{mV} /$ decade of activity at $25 \circ \mathrm{C}$, and $a\left(\mathrm{AN}^{-}\right)=$activity of the surfactant anion.

It follows from Eq. (5) that the magnitude of the emf changes in the course of titration greatly depends on the $K_{\mathrm{sp}}$ value of ion-pair formed during titration. Lower $K_{\mathrm{sp}}$ values cause a greater emf change at the equivalence point, resulting in a more sensitive surfactant determination. If the difference between $\mathrm{p} K_{\mathrm{sp}}$ values of ion-pairs formed during titration of anionic surfactants mixture is $2-3$ units, the effectively separated inflexions are obtained on the titration curve, which enable the determination of individual surfactants in the mixture.

The main application of surfactant potentiometric sensor is for indication of the end-point at ionic surfactant potentiometric titrations (Equation 1).

The response of the new sensor, based on functiona-

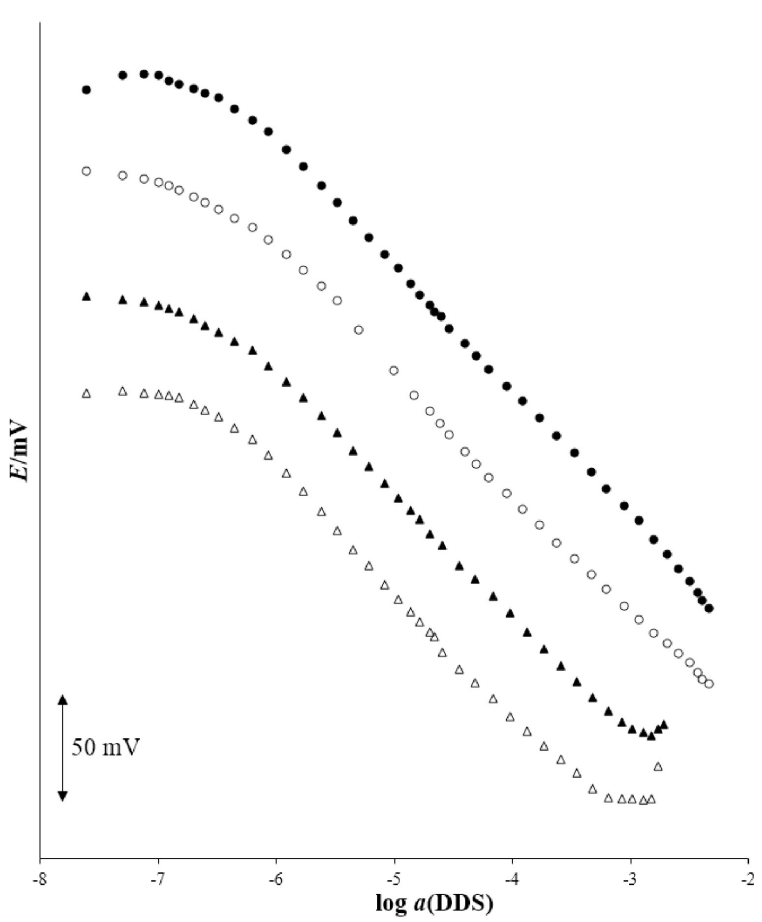

Figure 1. Responses of the FCNSS to DS and DBS in water and in $10 \mathrm{mM} \mathrm{Na}_{2} \mathrm{SO}_{4}$. Here and in further figures, some curves are displaced laterally and/or vertically for clarity ( DS in water; O DS in $\mathrm{Na}_{2} \mathrm{SO}_{4} ; \boldsymbol{\Delta}$ DBS in water; $\triangle \mathrm{DBS}$ in $\mathrm{Na}_{2} \mathrm{SO}_{4}$ ).

lized nanomaterial (FCNSS) was investigated in solutions of $\mathrm{NaDS}$ and NaDBS in a concentration range between 2.5 . $10^{-8}$ and $5 \cdot 10^{-3} \mathrm{M}$ in pure aqueous solutions and in $0.01 \mathrm{M}$ $\mathrm{Na}_{2} \mathrm{SO}_{4}$ (to explore the influence of ionic strength). The measured responses are shown in Figure 1.

At higher concentration region (above $1 \cdot 10^{-3} \mathrm{M}$ ) the divergences from linearity at some responses are observed, which are caused by the formation of micelles (in the vicinity of critical micellar concentration, CMC). Davies equation was used for calculation of the activity coefficients. The response characteristics of the sensor were estimated by means of linear regression analysis and the results are shown in Table 1.

Table 1. The response characteristics and their statistics of the FCNSS to DS and DBS(a)

\begin{tabular}{|c|c|c|c|c|c|}
\hline Parameters & $\begin{array}{c}\text { Slope }[\mathrm{mV} / \text { decade } \\
\text { of activity] }\end{array}$ & $\begin{array}{c}\text { Standard error } \\
\text { [mV/decade of } \\
\text { activity] }\end{array}$ & $\begin{array}{l}\text { Correl. } \\
\text { coeff. }\left[R^{2}\right]\end{array}$ & $\begin{array}{l}\text { Lower limit of } \\
\text { detection [M] }\end{array}$ & Useful conc. range $[\mathrm{M}]$ \\
\hline $\mathrm{NaDS}$ in $\mathrm{H}_{2} \mathrm{O}$ & $57.1 \pm 0.5$ & 1.5 & 0.9995 & $1.5 \cdot 10^{-7}$ & $3.2 \cdot 10^{-7}-5.0 \cdot 10^{-3}$ \\
\hline $\mathrm{NaDS}$ in $\mathrm{Na}_{2} \mathrm{SO}_{4} 0.01 \mathrm{M}$ & $54.6 \pm 1.0$ & 3.1 & 0.9979 & $2.0 \cdot 10^{-7}$ & $4.5 \cdot 10^{-7}-5.0 \cdot 10^{-3}$ \\
\hline $\mathrm{NaDBS}$ in $\mathrm{H}_{2} \mathrm{O}$ & $54.4 \pm 0.6$ & 1.5 & 0.9993 & $2.0 \cdot 10^{-7}$ & $4.5 \cdot 10^{-7}-1.2 \cdot 10^{-3}$ \\
\hline $\mathrm{NaDBS}$ in $\mathrm{Na}_{2} \mathrm{SO}_{4} 0.01 \mathrm{M}$ & $55.2 \pm 1.2$ & 2.9 & 0.9972 & $2.0 \cdot 10^{-7}$ & $3.2 \cdot 10^{-7}-6.5 \cdot 10^{-4}$ \\
\hline
\end{tabular}

(a) average of 5 determinations \pm confidence limits $(p=0.95)$. 
Table 2. The comparison of the new sensor with a few other potentiometric surfactant sensors

\begin{tabular}{|c|c|c|c|c|c|c|c|c|c|}
\hline $\begin{array}{l}\text { Type of the } \\
\text { electrode }\end{array}$ & Ionophore & Analyte & $\begin{array}{c}\text { Slope } \\
\text { [mV/decade } \\
\text { of activity] }\end{array}$ & $\begin{array}{c}\text { Correl. } \\
\text { coeff. } \\
{\left[R^{2}\right]}\end{array}$ & $\begin{array}{l}\text { Lower limit } \\
\text { of detection } \\
{[\mathrm{M}]}\end{array}$ & $\begin{array}{l}\text { Useful conc. } \\
\text { range [M] }\end{array}$ & $\begin{array}{l}\text { Response } \\
\text { time / s }\end{array}$ & $\begin{array}{l}\text { Working } \mathrm{pH} \\
\text { range }\end{array}$ & $\begin{array}{l}\text { Life time / } \\
\text { months }\end{array}$ \\
\hline $\begin{array}{l}\text { ISE with liquid } \\
\text { membrane } \\
\text { (FCNSS) }\end{array}$ & $\begin{array}{l}\text { MWCNT- } \\
\text { TODA-TPB }\end{array}$ & $\begin{array}{l}\mathrm{NaDDS} \text { in } \mathrm{H}_{2} \mathrm{O} \\
\mathrm{NaDBS} \text { in } \mathrm{H}_{2} \mathrm{O}\end{array}$ & $\begin{array}{l}57.1 \pm 0.5 \\
54.4 \pm 0.6\end{array}$ & $\begin{array}{l}0.9995 \\
0.9993\end{array}$ & $\begin{array}{l}1.5 \cdot 10^{-7} \\
2.0 \cdot 10^{-7}\end{array}$ & $\begin{array}{l}3.2 \cdot 10^{-7}-5.0 \cdot 10^{-3} \\
4.5 \cdot 10^{-7}-1.2 \cdot 10^{-3}\end{array}$ & 8 & $2-10$ & 6 \\
\hline $\begin{array}{l}\text { Solid state } \\
\text { sensor [21] }\end{array}$ & $\begin{array}{l}\text { MWCNT- } \\
\mathrm{OSO}_{3}-\mathrm{CP}^{+(a)}\end{array}$ & $\begin{array}{l}\mathrm{NaDDS} \text { in } \mathrm{H}_{2} \mathrm{O} \\
\mathrm{NaDBS} \text { in } \mathrm{H}_{2} \mathrm{O}\end{array}$ & $\begin{array}{l}52.9 \pm 1.0 \\
51.2 \pm 1.5\end{array}$ & $\begin{array}{l}0.9993 \\
0.9962\end{array}$ & $\begin{array}{l}1.5 \cdot 10^{-6} \\
2.5 \cdot 10^{-6}\end{array}$ & $\begin{array}{l}3.6 \cdot 10^{-6}-5.0 \cdot 10^{-3} \\
4.2 \cdot 10^{-6}-9.1 \cdot 10^{-4}\end{array}$ & 5 & $3-10$ & 6 \\
\hline $\begin{array}{l}\text { ISE with liquid } \\
\text { membrane [5] }\end{array}$ & $\begin{array}{c}\mathrm{DDA}^{(\mathrm{b})}{ }_{-} \mathrm{TPB}+ \\
10 \% \mathrm{C}\end{array}$ & $\begin{array}{l}\mathrm{NaDDS} \text { in } \mathrm{H}_{2} \mathrm{O} \\
\mathrm{NaDBS} \text { in } \mathrm{H}_{2} \mathrm{O}\end{array}$ & $\begin{array}{l}55.3 \pm 0.9 \\
58.5 \pm 1.7\end{array}$ & $\begin{array}{l}0.9987 \\
0.9940\end{array}$ & $\begin{array}{l}2.5 \cdot 10^{-7} \\
2.0 \cdot 10^{-7}\end{array}$ & $\begin{array}{l}3.2 \cdot 10^{-7}-4.6 \cdot 10^{-3} \\
2.5 \cdot 10^{-7}-1.2 \cdot 10^{-3}\end{array}$ & 5 & $3-12$ & 5 \\
\hline $\begin{array}{l}\text { All-solid state } \\
\text { sensor [19] }\end{array}$ & $\begin{array}{l}\text { DDA-TPB + } \\
\text { graphene }\end{array}$ & $\begin{array}{l}\mathrm{NaDDS} \text { in } \mathrm{H}_{2} \mathrm{O} \\
\mathrm{NaDBS} \text { in } \mathrm{H}_{2} \mathrm{O}\end{array}$ & $\begin{array}{l}47.6 \pm 0.4 \\
59.2 \pm 1.5\end{array}$ & $\begin{array}{l}0.9993 \\
0.9951\end{array}$ & $\begin{array}{l}1.5 \cdot 10^{-7} \\
2.5 \cdot 10^{-7}\end{array}$ & $\begin{array}{l}2.5 \cdot 10^{-7}-4.5 \cdot 10^{-3} \\
3.0 \cdot 10^{-7}-2.5 \cdot 10^{-3}\end{array}$ & 12 & $2-7$ & 3 \\
\hline $\begin{array}{l}\text { ISE with liquid } \\
\text { membrane [22] }\end{array}$ & $\mathrm{L}^{1(\mathrm{c})}$ & $\mathrm{NaDDS}$ in $\mathrm{H}_{2} \mathrm{O}$ & 59.5 & - & $6.0 \cdot 10^{-7}$ & $1.3 \cdot 10^{-6}-6.8 \cdot 10^{-3}$ & 3 & $5-8$ & 0.33 \\
\hline $\begin{array}{l}\text { ISE with liquid } \\
\text { membrane [23] }\end{array}$ & PPy-DBS(d) & $\mathrm{NaDBS}$ in $\mathrm{H}_{2} \mathrm{O}$ & 57.2 & - & $2.0 \cdot 10^{-5}$ & $3.0 \cdot 10^{-5}-3.0 \cdot 10^{-3}$ & 20 & $3-10$ & 6 \\
\hline
\end{tabular}

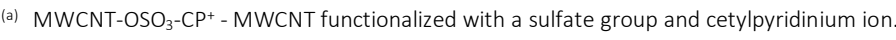

(b) DDA - dimethyldioctadecylammonium cation.

(c) L1 - 7-methyl-7,13-di-octyl-1,4,10-trioxa-13-aza-7-azonia-cyclopentadecane.

(d) PPy-DBS - dodecylbenzenesulfonate-doped polypyrrole.
}

The detection limits were estimated according to the IUPAC recommendations. ${ }^{[19]}$

The investigated sensor revealed a sub-Nernstian response for both DS and DBS in $\mathrm{H}_{2} \mathrm{O}$ (57.1 and 54.4 $\mathrm{mV} /$ decade of activity, respectively) between $3.2 \cdot 10^{-7}$ and $5.0 \cdot 10^{-3} \mathrm{M}$ for dodecyl sulfate (DS) and $4.5 \cdot 10^{-7}$ and 1.2 . $10^{-3} \mathrm{M}$ for dodecylbenzenesulfonate (DBS).

It also exhibited a sub-Nernstian response for both DS and DBS in $0.01 \mathrm{M} \mathrm{Na}_{2} \mathrm{SO}_{4}$ (54.6 and $55.2 \mathrm{mV} /$ decade of activity, respectively) between $4.5 \cdot 10^{-7}$ and $5.0 \cdot 10^{-3} \mathrm{M}$ for DS and $3.2 \cdot 10^{-7}$ and $6.5 \cdot 10^{-4} \mathrm{M}$ for DBS.

The comparison of the most important analytical and physicochemical characteristics of the new FCNSS with a few other potentiometric surfactant sensors is shown in Table 2. It can be concluded that FCNSS exhibited the longest lifetime combined with the lowest limit of detection and the highest $\mathrm{E}$ vs. $\log a\left(\mathrm{AN}^{-}\right)$correlation.

\section{Dynamic Response Measurements}

The response time of the sensor was estimated by measuring the time needed for the sensor to acquire $90 \%$ of the final value after a sudden change (increase) of surfactant concentration. Figure 2 displays the dynamic responses of the new FCNSS to DS in water.

As shown in Figure 2, the sensor responded within 8 $s$ for changes at a higher concentration level (above $1 \cdot 10^{-4}$ $\mathrm{M})$, and $12 \mathrm{~s}$ for changes at lower concentrations (below 1 . $\left.10^{-5} \mathrm{M}\right)$.

\section{Signal Drift}

Sensor drift can be defined as a progressive signal variation with time in the electromotive force (emf). It can be caused by various factors, such as temperature changes, stabilizing

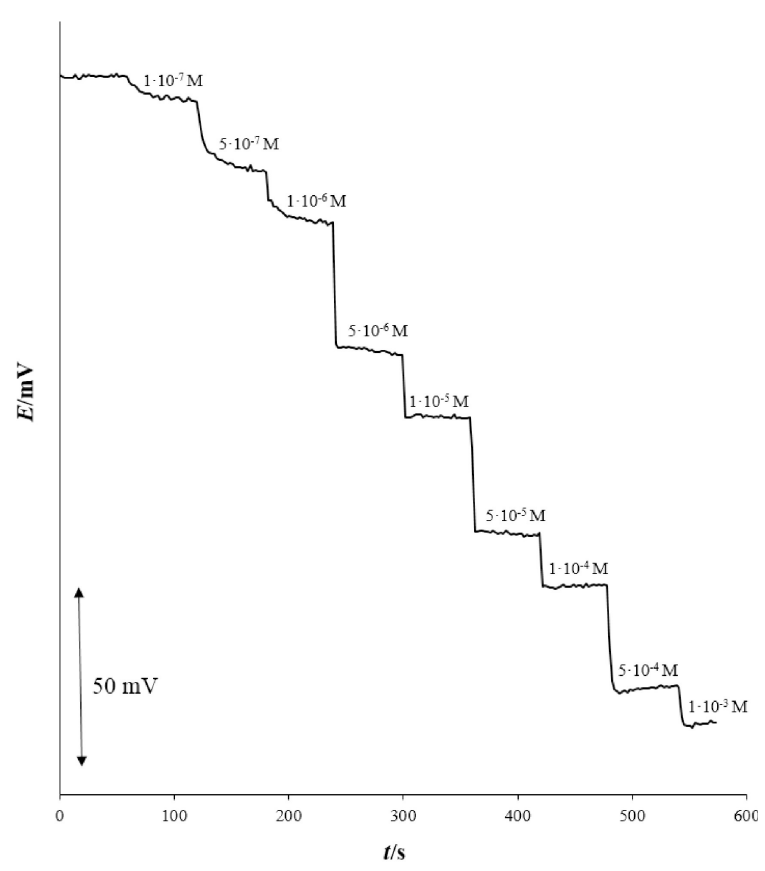

Figure 2. Dynamic responses of the FCNSS to DS in $\mathrm{H}_{2} \mathrm{O}$. 
Table 3. The comparison of the potentiometric selectivity coefficients for different anions most frequently used in commercial products for the FCNSS with those obtained using a few other potentiometric surfactant sensors

\begin{tabular}{|c|c|c|c|c|c|}
\hline & \multicolumn{5}{|c|}{ Ionophore } \\
\hline & $\begin{array}{c}\text { MWCNT-TODA- } \\
\text { TPB (FCNSS) }\end{array}$ & $\begin{array}{c}\text { DDA-TPB + } \\
10 \% C^{[5]}\end{array}$ & DDA-TPB + graphene ${ }^{[19]}$ & $\mathrm{L}^{1}[22]$ & PPy-DBS ${ }^{[23]}$ \\
\hline Interference & \multicolumn{5}{|c|}{$p K_{i j}^{p o t}$} \\
\hline Chloride & 3.91 & 3.68 & 4.19 & 3.82 & 2.46 \\
\hline lodide & 4.46 & 4.47 & 3.47 & 3.39 & 2.47 \\
\hline Fluoride & 4.45 & 4.05 & 3.39 & - & 2.46 \\
\hline Carbonate & 5.32 & 4.40 & 4.21 & - & - \\
\hline Hydrogen carbonate & 4.17 & 3.75 & 2.36 & 3.45 & - \\
\hline Nitrite & 4.52 & 4.14 & 3.25 & 3.71 & 2.36 \\
\hline Nitrate & 4.33 & 3.85 & 3.39 & 3.67 & 2.20 \\
\hline Sulfate & 5.21 & 5.55 & 3.75 & 5.06 & - \\
\hline Phosphate & 5.34 & 4.19 & 4.43 & 4.10 & - \\
\hline Dihydrogen phosphate & 4.26 & 4.13 & 3.26 & - & 2.39 \\
\hline Borate & 5.16 & 4.12 & 3.64 & - & - \\
\hline Acetate & 4.41 & 3.78 & 4.62 & 3.37 & 2.15 \\
\hline Benzoate & 4.28 & 3.60 & 3.14 & - & - \\
\hline Citrate & 5.45 & 4.70 & 4.26 & - & - \\
\hline Ethylenediamine tetraacetate & 5.19 & 5.48 & 4.41 & - & - \\
\hline Sulfamate & 4.48 & 4.09 & 3.77 & - & - \\
\hline Xylene sulfonate & 3.59 & 3.59 & 2.82 & - & - \\
\hline Toluene sulfonate & 4.41 & 3.89 & 2.70 & - & - \\
\hline
\end{tabular}

of electronics, aging and contamination of the membrane, memory effects, influence of matrix, sample decomposition, etc. The drift was measured in $1 \mathrm{mM}$ solution of $\mathrm{NaDS}$ at 25 으 and estimated by linear curve fitting on the data set in a designated time interval. It can be defined as the slope of the calculated linear regression line that represented the dependence of emf as a function of time.

For the new FCNSS, this dependence is given by the equation

$E(\mathrm{mV})=-0.000581 \cdot \mathrm{t}(\mathrm{s})-157.9$, i.e. the calculated drift amounted to $2.1 \mathrm{mV} /$ hour.

The lifetime of the sensor depends on the sample complexity and was approximately five months by using the sensor in aqueous solutions in the absence of strongly interfering matrix components (fats, oils, suspended matter).

\section{Determination of the Potentiometric Selectivity Coefficients}

The response of the new surfactant sensor in the presence of interferents can be described by the Nikolskii-Eisenman equation:
$E=E^{\circ}\left(\mathrm{A}_{\text {det }}^{-}\right)-\frac{R T}{F} \cdot \ln \left[a\left(A_{\text {det }}^{-}\right)+K^{\text {pot }}\left(\mathrm{A}_{\text {det }}^{-} \mathrm{A}_{\text {int }}^{-}\right) a\left(A_{\text {int }}^{-}\right)\right](6)$

where $K^{\text {pot }}\left(A_{\text {det }}^{-} A_{\text {int }}^{-}\right)$is the potentiometric selectivity coefficient and $a\left(A_{\mathrm{det}}^{-}\right)$and $a\left(A_{\text {int }}^{-}\right)$are the activities of the analyte ion (det) and the interfering ion (int), respectively.

For the determination of the potentiometric selectivity coefficients in the investigations described, the fixed interference method (FIM) was applied. [20]

The calculation and optimization of the potentiometric selectivity coefficients was accomplished using Solver, a Microsoft Excel analysis tool. The experimental data obtained by the FIM were fitted to the Nikolskii-Eisenman equation.

The list of the potentiometric selectivity coefficients of some inorganic and organic anions usually found in surfactant-based products for the FCNSS compared with those calculated for a few other potentiometric surfactant sensors is shown in Table 3.

At all the selectivity measurements, DS was used as the analyte, in the range from $2 \cdot 10^{-6} \mathrm{M}$ to $2 \cdot 10^{-3} \mathrm{M}$, whereas the concentration of the interfering ion was $0.01 \mathrm{M}$. 


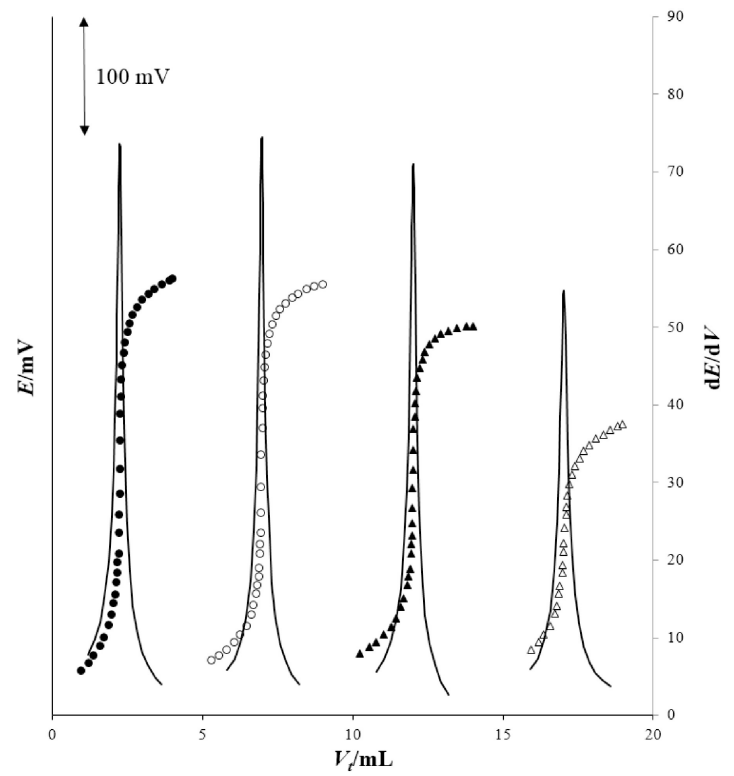

Figure 3. Potentiometric titration curves and their first derivatives for $4 \mathrm{mM}$ DS using different cationic surfactants ( $c=4 \mathrm{mM}$ ) as the titrants and the new FCNSS as the endpoint detector (DMIC $(\bullet), \operatorname{CPC}(\mathrm{O}), \operatorname{CTAB}(\boldsymbol{\Delta})$ and Hyamine $(\Delta))$.

The new FCNSS exhibited excellent selectivity for DS over all of the anions investigated. Comparing with other potentiometric surfactant sensors, FCNSS revealed superior selectivity performances.

\section{The Influence of $\mathrm{pH}$}

Due to the fact that commercial products based on anionic surfactants may have different $\mathrm{pH}$ values, it was necessary to test the applicability of the new electrode over a wide $\mathrm{pH}$ range. The new electrode exhibited stable potential without significant deviations in the the $\mathrm{pH}$ range between $\mathrm{pH} 2$ and $\mathrm{pH} 10$ (figure not shown).

\section{Selection of the Titrant}

Determination of anionic surfactants is usually carried out by titration, thus the selection of an appropriate titrant is of great significance. The most used for this purpose are cationic titrants. The standard solutions $\left(c=4 \cdot 10^{-3} \mathrm{M}\right)$ of the following cationic surfactants: Hyamine 1622, CTAB, CPC and DMIC were tested as potential titrants in the investigations presented. A standard solution of $\operatorname{NaDS}(c=$ $4 \cdot 10^{-3} \mathrm{M}$ ) was applied as the analyte and the new FCNSS served as an end-point indicator (Figure 3 ). Table 4.

The results and corresponding statistics are shown in

Due to its best analytical performances, CPC was used in further investigations.

The most appropriate titrant concentration for determination of anionic surfactants in different commercial formulations is $c=4 \cdot 10^{-3} \mathrm{M}$. The new FCNSS exhibited a wide linear working range and low detection limits, which indicates its potential use for determination of low levels of ASs too (in effluents, surface waters etc.). For this purpose, a series of diluted standard CPC solutions of concentrations $c=1 \cdot 10^{-3}, 4 \cdot 10^{-4}, 7 \cdot 10^{-5}$ and $4 \cdot 10^{-5} \mathrm{M}$ were tested as potential titrants for potentiometric determination of ASs at micromolar level.

Still CPC at a concentration $7 \cdot 10^{-5} \mathrm{M}$ delivered an analytically useful titration curve (figure not shown).

\section{Titration of a Three-component Mixture}

Commercial products formulations often contain a combination of two or more anionic surfactants with the aim to improve certain product features. Among the important sensor characteristics belongs its capability to distinguish between individual surfactants in a mixture. For this purpose a mixture of three alkanesulfonates of different hydrophobic chain length $\left(C_{10}, C_{12}\right.$ and $\left.C_{14}\right)$ was potentiometrically titrated resulting in three wellseparated inflexions in the titration curve (Figure 4).

Table 4. Statistics of NaDS determination obtained using FCNSS as end-point detector and different titrants $(c=4 \mathrm{mM})^{(\mathrm{a})}$

\begin{tabular}{|c|c|c|c|c|c|}
\hline \multirow{2}{*}{\multicolumn{2}{|c|}{ Parameters }} & \multicolumn{4}{|c|}{ Titrants } \\
\hline & & CPC & DMIC & CTAB & Hyamine \\
\hline \multicolumn{2}{|c|}{ Potential jump in EP/mV } & 323.2 & 330.0 & 280.5 & 191.8 \\
\hline \multicolumn{2}{|c|}{ Potential value in $\mathrm{EP} / \mathrm{mV}$} & $-11.3 \pm 2.6$ & $-26.2 \pm 20.3$ & $-11.7 \pm 3.5$ & $-105.7 \pm 5.0$ \\
\hline \multicolumn{2}{|c|}{ First derivative values in $\mathrm{EP} / \mathrm{mV} / \mathrm{mL}$} & $74.6 \pm 0.2$ & $73.3 \pm 0.4$ & $71.0 \pm 0.6$ & $54.4 \pm 0.8$ \\
\hline \multicolumn{2}{|c|}{ Accuracy $/ \%$} & 98.4 & 112.1 & 101.0 & 101.0 \\
\hline \multirow{3}{*}{ Precision } & SD & 0.550 & 0.921 & 0.319 & 0.782 \\
\hline & RSD & 0.0056 & 0.0082 & 0.0032 & 0.0077 \\
\hline & CV & 0.559 & 0.822 & 0.316 & 0.774 \\
\hline
\end{tabular}

(a) average of 5 determinations \pm confidence limits $(p=0.95)$. 


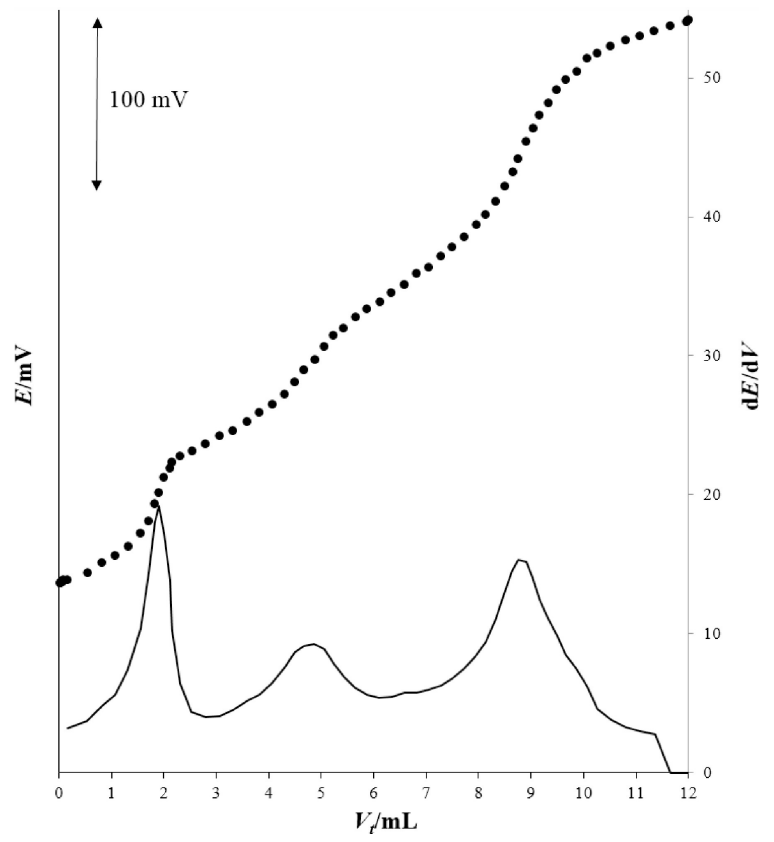

Figure 4. Potentiometric titration curves and their first derivatives for the three-component mixture of alkane sulfonates $\left(C_{10}, C_{12}\right.$ and $C_{14,} C=1 \mathrm{mM}$ each) using the new FCNSS as the end-point detector and $1 \mathrm{mM} \mathrm{CPC}$ as the titrant (C10:C12:C14= 4:3:2).

Although the difference between the surfactants was only two $\mathrm{C}$ atoms, the end-points located by means of their first derivative were analytically usable.

The results of the single surfactants content in the mixture are shown in Table 5.

\section{Influence of Nonionic Surfactants}

The commercial product formulations are often optimized using a combination of anionic and nonionic surfactants, and from the latter, the ethoxylated nonionic surfactants (EONS) are most commonly used. Their compatibility with other nonionic and anionic surfactants opens up the new possibilities in product development. Among the most frequently used types of EONS are ethoxylated fatty alcohols, which influence the shape of potentiometric titration curves of ASs.

In Figure 5, the influence of the number of EO groups in each particular surfactant on the shape of the titration curves was shown. The molar ratio of NaDS and EONS by all investigations was 1:2, respectively. The explored EONS contained 8, 11 and $15 \mathrm{EO}$ groups. It can be seen that EONS with higher EO content have a stronger influence on the potentiometric titration, but the magnitude of the electrode potential jump at the inflexion was still sufficient for a reliable endpoint location.
Table 5. The results of determination of single alkanesulfonates in a mixture obtained using FCNSS as endpoint detector and $\mathrm{CPC}\left(c=1 \cdot 10^{-3} \mathrm{M}\right)$ as the titrant

\begin{tabular}{lccc}
\hline $\begin{array}{l}\text { Alkan } \\
\text { sulfonate }\end{array}$ & $\begin{array}{c}\text { Added } \\
{[\mathrm{mol}]}\end{array}$ & $\begin{array}{c}\text { Found [mol] } \pm \\
\text { RSD [\%] }\end{array}$ & $\begin{array}{c}\text { Recovery } \\
{[\%]^{(\mathrm{a})}}\end{array}$ \\
\hline C10 & $4 \cdot 10^{-6}$ & $3.98 \cdot 10^{-6} \pm 1.0$ & 99.5 \\
C12 & $3 \cdot 10^{-6}$ & $2.88 \cdot 10^{-6} \pm 1.0$ & 96.0 \\
C14 & $2 \cdot 10^{-6}$ & $1.95 \cdot 10^{-6} \pm 1.1$ & 97.5 \\
\hline
\end{tabular}

(a) average of 3 determinations.

The concentration of EONS affected the shape of potentiometric titration curves too, which was demonstrated in the example of Genapol 080 (8 EO groups), as shown in Figure 6.

The extent of the inflexion decreased with increasing concentration of EONS, resulting in slight distortion of the titration curves, but still making location of the end-point reliable.

\section{Titration of Commercial Products and Effluents}

The quantification of ASs in various commercial products (household and industrial detergents, cosmetics, pharma-

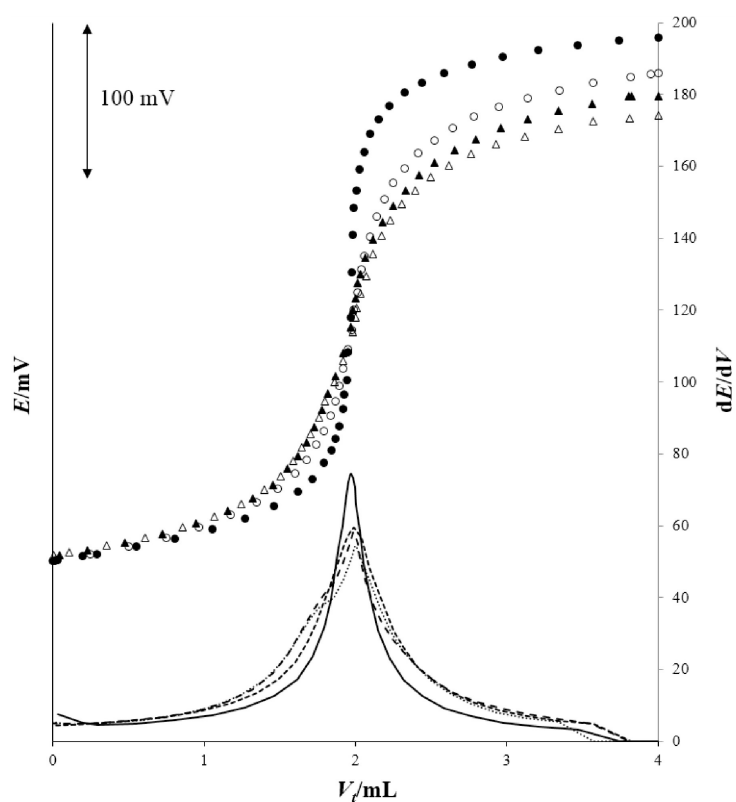

Figure 5. The titration curves and their first derivatives for DS using $4 \mathrm{mM} \mathrm{CPC}$ as the titrant and the new FCNSS as the end-point detector in the presence of EONS of different EO group contents at a fixed DS:EONS molar ratio of $1: 2(\bullet,-$ DS alone; $0,---8$ EO groups; $\boldsymbol{\Lambda},--11$ EO groups; $\Delta, \cdots$ 15 EO groups). 


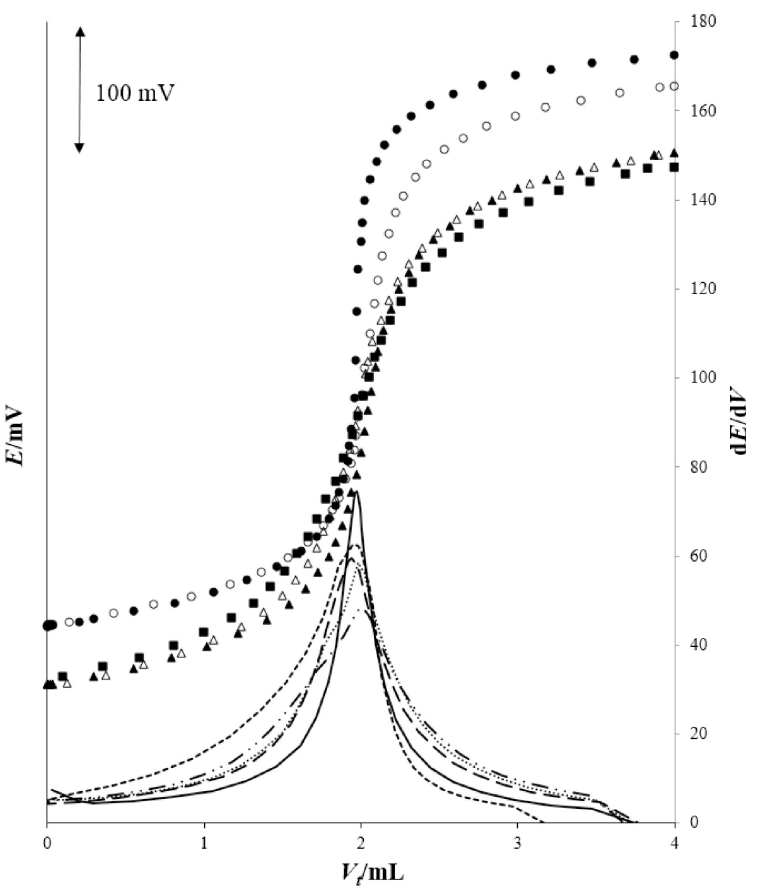

Figure 6. The influence of concentration of EONS (8 EO groups) on the titration curves and their first derivatives for the DS titration using $4 \mathrm{mM} \mathrm{CPC}$ as the titrant and the new FCNSS as the end-point detector $(\bullet,-$ DS alone; DS:Genapol T 080 at molar ratios of O, --- 1:1; $\boldsymbol{\Lambda},--1: 2$; $\Delta, \cdots 1: 3$, and $\mathbf{m},-\cdot-1: 5)$.

ceuticals, etc.) is one of the principal uses of surfactant potentiometric sensors.

For this purpose, three commercial products (liquid soap, liquid hand-dishwashing detergent, gel detergent) were titrated with a $4 \mathrm{mM} \mathrm{CPC}$ solution as the titrant. The new FCNSS was used as an end-point detector.

The influence of the matrix, accuracy and precision of the determination were tested using the standard addition method by adding one or more increments of the standard NaDS solution to sample aliquots. The obtained potentiometric titration curves exhibited well-defined inflections resulting in reliable end-point detection (Figure 7).

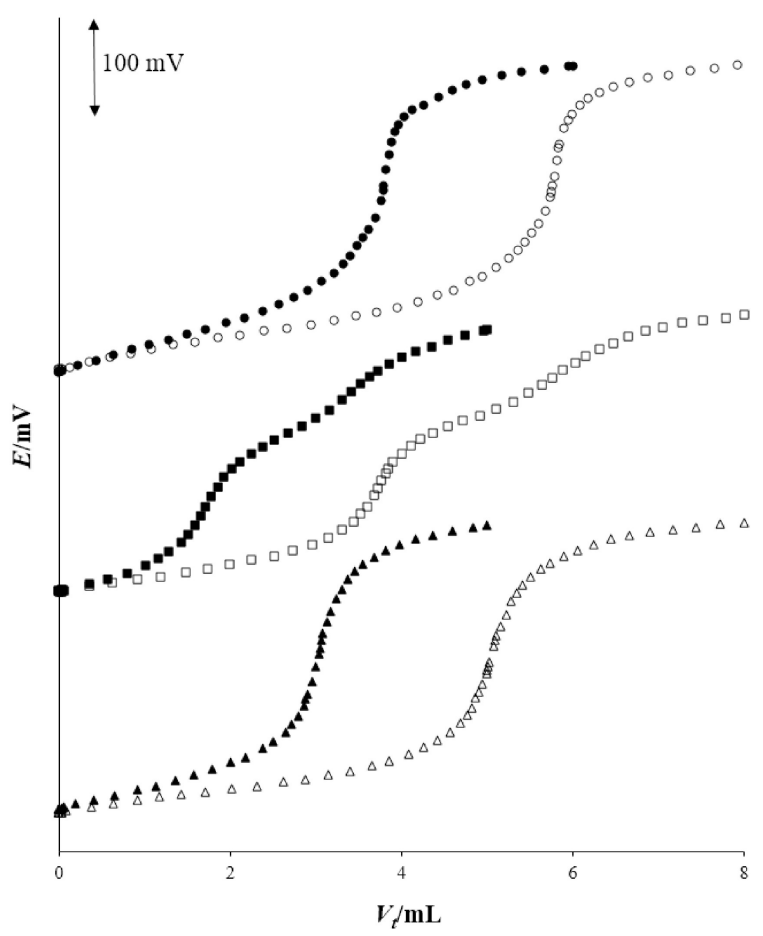

Figure 7. Titration curves for three commercial detergents with the addition of known amounts of 4 mM DS obtained using $4 \mathrm{mM} \mathrm{CPC}$ as the titrant and the new FCNSS as an endpoint detector ( $\bullet$ liquid soap, o liquid soap $+2 \mathrm{~mL} \mathrm{DS}$, liquid hand-dishwashing detergent, $\square$ liquid handdishwashing detergent $+2 \mathrm{~mL}$ DS, $\boldsymbol{\Delta}$ gel detergent, $\Delta$ gel detergent $+2 \mathrm{~mL}$ DS).

The $\mathrm{pH}$ value of the sample solutions was adjusted to 3 before titration. No ionic strength adjustment was necessary. The results and corresponding statistics of the determination of ASs in the products investigated are shown in Table 6. The obtained recoveries ranged from 98.2 to $100.4 \%$, indicating a satisfactory accuracy of the determination of ASs.

The ASs content was also determined using the standard two-phase titration method and the results obtained were compared with those acquired using the new FCNSS (Table 7).

Table 6. Results of the potentiometric determinations of ASs in the commercial detergents and with the addition of known amounts of NaDS solution, using $4 \mathrm{mM} \mathrm{CPC}$ as the titrant and the new FCNSS as the end-point detector

\begin{tabular}{lcccc}
\hline Detergent type & AS found [mol L-1] \pm RSD [\%] $]^{\mathrm{a})}$ & NaDS added [mol] & $\begin{array}{c}\text { NaDS found [mol] } \pm \\
\text { RSD [\%] }]^{\mathrm{a})}\end{array}$ & Recovery [\%] $]^{\mathrm{a})}$ \\
\hline 1 & $1.01 \cdot 10-3 \pm 0.5$ & $8.00 \cdot 10-6$ & $7.86 \cdot 10-6 \pm 0.3$ & 98.2 \\
2 & $1.39 \cdot 10-3 \pm 1.1$ & $8.00 \cdot 10-6$ & $8.03 \cdot 10-6 \pm 0.3$ & 100.4 \\
3 & $1.22 \cdot 10-3 \pm 0.3$ & $8.00 \cdot 10-6$ & $8.01 \cdot 10-6 \pm 0.3$ & 100.1 \\
\hline
\end{tabular}

(a) average of 5 determinations \pm confidence limits $(p=0.95)$. 
Table 7. Results of the potentiometric determinations of ASs content in the commercial detergents using $4 \mathrm{mM} \mathrm{CPC}$ as the titrant and the FCNSS as an end-point detector compared to the results obtained using the two-phase titration method

\begin{tabular}{lcc}
\hline $\begin{array}{l}\text { Detergent } \\
\text { type }\end{array}$ & $\begin{array}{c}\text { AS content using } \\
\text { FCNSS [\%] }]^{(a)}\end{array}$ & $\begin{array}{c}\text { AS content using two- } \\
\text { phase titration [\%] }\end{array}$ \\
\hline 1 & 3.53 & 3.23 \\
2 & 9.67 & 9.63 \\
3 & 8.47 & 8.41 \\
\hline
\end{tabular}

(a) average of 5 determinations.

(b) average of 3 determinations.

A satisfactory agreement was found between the results obtained using the potentiometric method and those obtained by the standard two-phase titration.

The new FCNSS was tested on three different samples of industrial effluents. All of the samples were filtered and the $\mathrm{pH}$ was adjusted to 3 before titration. The ionic strength was not adjusted.

The standard addition method was used to determine the accuracy, precision and influence of the matrix on the ASs determination.

The corresponding titration curves are displayed in Figure 8 and they revealed a satisfactory inflexion at the end-point using $0.1 \mathrm{mM} \mathrm{CPC}$ as the titrant. The volume of titrant at the end-point was calculated from the derivative curves or by Savitzky-Golay-Barak method. The results of the determinations are shown in Table 8.

The obtained recoveries were in the range between 87.3 and $103.8 \%$, which is acceptable for the determination of ASs in effluents. The differences in recoveries for some effluents are caused by dissimilarities in their complexity.

The results obtained with the new FCNSS compared with those obtained by the standard MBAS procedure are shown in Table 9.

It can be concluded that a satisfactory correlation existed between the both methods.

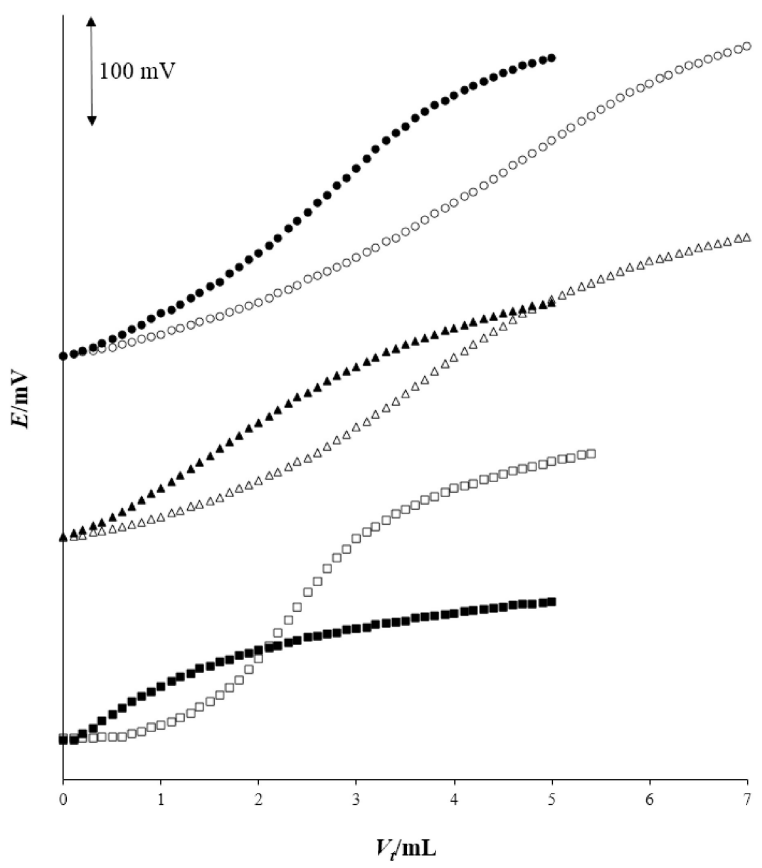

Figure 8. Titration curves for industrial wastewaters with the addition of known amounts of $0.1 \mathrm{mM}$ DS obtained using $0.1 \mathrm{mM} \mathrm{CPC}$ as the titrant and the new FCNSS as an endpoint detector ( sample 1, o sample $1+2 \mathrm{mLDS}, \boldsymbol{\Delta}$ sample 2, $\Delta$ sample $2+2 \mathrm{mLDS}$, sample 3 , $\square$ sample $3+2 \mathrm{mLDS}$ ).

\section{CONCLUSION}

A new anionic surfactant sensitive sensor was prepared, containing multi-walled carbon nanotubes noncovalently functionalized with tetraoctadecylammonium tetraphenylborate, that was used as sensing material and embedded in a PVC liquid membrane. The sensor responded fast and revealed a considerably reduced signal drift compared to conventional ion-pair based sensors. Its main use is for endpoint detection at the potentiometric titration of anionic surfactants. The resulting titration curves exhibited a clear inflexion providing a reliable end-point evaluation. The new sensor revealed outstanding selectivity for DS against almost all particular anions usually present in commercial

Table 8. Results of the potentiometric determination of ASs in industrial wastewater and with the addition of known volumes of standard NaDS solution using the FCNSS as an end-point detector and $0.1 \mathrm{mM} \mathrm{CPC}$ as the titrant

\begin{tabular}{|c|c|c|c|c|}
\hline Wastewater sample & AS found $\left[\mathrm{mol} \mathrm{L}^{-1}\right] \pm \mathrm{RSD}[\%]^{(\mathrm{a})}$ & $\mathrm{NaDS}$ added [mol] & $\begin{array}{l}\mathrm{NaDS} \text { found }[\mathrm{mol}] \pm \\
\operatorname{RSD}[\%]^{\mathrm{a})}\end{array}$ & Recovery $[\%]^{(\mathrm{a})}$ \\
\hline 1 & $2.76 \cdot 10^{-5} \pm 3.1$ & $2.00 \cdot 10^{-7}$ & $2.08 \cdot 10^{-7} \pm 5.0$ & 103.8 \\
\hline 2 & $1.65 \cdot 10^{-5} \pm 4.5$ & $2.00 \cdot 10^{-7}$ & $1.81 \cdot 10^{-7} \pm 3.5$ & 90.4 \\
\hline 3 & $3.55 \cdot 10^{-6} \pm 11.9$ & $2.00 \cdot 10^{-7}$ & $1.75 \cdot 10^{-7} \pm 3.6$ & 87.3 \\
\hline
\end{tabular}

(a) average of 5 determinations \pm confidence limits $(p=0.95)$. 
Table 9. Comparison of results of ASs content obtained with the new FCNSS and those obtained using the MBAS method

\begin{tabular}{|c|c|c|}
\hline $\begin{array}{l}\text { Wastewater } \\
\text { sample }\end{array}$ & $\begin{array}{l}\text { AS content using } \\
\text { FCNSS }\left[\mathrm{mg} \mathrm{L}^{-1}\right]^{\mathrm{a})}\end{array}$ & $\begin{array}{l}\text { AS content using MBAS } \\
\text { method }\left[\mathrm{mg} \mathrm{L}^{-1}\right]^{\text {b) }}\end{array}$ \\
\hline 1 & 9.64 & 9.82 \\
\hline 2 & 5.75 & 5.63 \\
\hline 3 & 1.24 & 1.40 \\
\hline
\end{tabular}

formulations based on anionic surfactants. The nonionic surfactants, commonly found in the commercial formulations, can affect the titration of anionic surfactants, resulting in a decrease of inflexion at titration curves, but still providing reliable end-point de-tection. The new sensor succeeded in single potentiometric determination of alkanesulfonates in their three-compo-nent mixture. It was successfully tested for the potentio-metric titration of ASs in the detergent products and industrial effluents, and the results obtained were in good accordance with those obtained using standard methods.

Acknowledgment. This work was supported by the Croatian Science Foundation under the project IP-11-2013-9060.

\section{REFERENCES}

[1] Acmite Market Intelligence, Market Report, Global Surfactant Market, $4^{\text {th }}$ ed., Ratingen, Germany, 2016.

[2] International Organization for Standardization, Water quality, Determination of surfactants, Part 1: Determination of anionic surfactants by the methylene blue spectrometric method, ISO 7875/1, Geneva, Switzerland, 1984.

[3] International Organization for Standardization, Surface active agents, Detergents, Determination of anionic-active matter by manual or mechanical direct two-phase titration procedure, ISO 2271, Geneva, Switzerland, 1989.
[4] E. Khaled, G. G. Mohamed, T. Awad, Sens. Actuators B 2008, 135, 74.

[5] M. Samardžić, O. Galović, M. Hajduković, M. SakBosnar, Talanta 2017, 162, 316.

[6] C. Crey-Desbiolles, S. Cavalli, S. Polesello, S. Valsecchi, Tens. Surf. Det. 2009, 49, 346.

[7] A. Escrig-Doménech, E. F. Simó-Alfonso, G. RamisRamos, Anal. Chim. Acta 2016, 932, 106.

[8] J. Alonso, J. Barb, J. Bartroli, J. Siinchez, M. de1 Valle, Anal. Chim. Acta 1995, 308, 115.

[9] F. Wei, R. Wang, H. Wang, Z. Wang, Huaxue Shijie 2010, 51, 466.

[10] M. Koga, Y. Yamamichi, Y. Nomoto, M. Irie, T. Tanimura, T, Yoshinaga, Anal. Sci. 1999, 15, 563.

[11] A. Adak, A. Pal, M. Bandyopadhyay, Ind. J. Chem. Tech. 2005, 12, 145.

[12] T. Masadome, Y. Yano, T. Imato, Anal. Lett. 2008, 41, 640.

[13] L. Taranova, I. Semenchuk, T. Manolov, P. Iliasov, A. Reshetilov, Biosens. Bioelectron. 2002, 17, 635.

[14] J. W. Wang, Z. P. Du, W. X. Wang, W. Xue, Russ. J. Electrochem. 2013, 49, 1101.

[15] M. Samardžić, O. Galović, S. Petrušić, M. Sak-Bosnar, Int. J. Electrochem. Sci. 2014, 9, 6166.

[16] G. A. Crespo, S. Macho, F. X. Rius, Anal. Chem. 2008, 80, 1316.

[17] T. Yin, W. Qin, Trends Anal. Chem. 2013, 51, 79.

[18] M. Ghaedi, S. Naderi, M. Montazerozohori, F. Taghizadeh, A. Asghari, Arab. J. Chem. 2013, doi:10.1016/j.arabjc.2013.11.029

[19] O. Galović, M. Samardžić, M. Hajduković, M. SakBosnar, Sens. Actuators, B 2016, 236, 257.

[20] International union of pure and applied chemistry, Pure Appl. Chem. 1994, 66, 2527.

[21] M. Hajduković, M. Samardžić, O. Galović, A. Széchenyi, M. Sak-Bosnar, Sens. Actuators, B 2017, 251, 795.

[22] M. J. Seguí, J. Lizondo-Sabater, A. Benito, R. Martínez-Máñez, T. Pardo, F. Sancenón, J. Soto, Talanta 2007, 71, 333.

[23] N. Alizadeh, H. Khodaei-Tazekendi, Sens. Actuators $B$ 2001, 75, 5. 